\title{
Comprehensive optimization of project cost for long supply pipelines
}

\author{
Abdulrahman Al-Khomairi* and BongSeog Jung** \\ *Civil Engineering Department, College of Engineering, Qassim University, Saudi Arabia \\ **Senior Hydraulic Specialist, HydraTek \& Associates, Vaughan, Ontario, Canada \\ *Corresponding Author: aalkhomairi@ksu.edu.sa, aalkhomairi@gmail.com
}

Submitted: $22 / 10 / 2019$

Revised: $\quad 05 / 02 / 2021$

Accepted: 15/02/2021

\begin{abstract}
This paper proposes a "comprehensive" pipeline design optimization approach that considers pipe parameters, protection device parameters, and project maintenance and operational costs over the pipeline's service life. The objective is to search for an optimal pipeline design by analyzing alternatives with different lifespans, while taking inflation and interest rates into account. A specially designed genetic algorithm routine suggests possible solutions that encompass a range of available pipe diameters, pipe materials, pipe pressure ratings, surge tank sizes, and inlet/ outlet resistances. With both steady-state and unsteady pipe flow analyses, the solution provides a system satisfying required demand without violating velocity and pressure constraints. A real-world project is selected to investigate the outcome of the optimization procedure. The proposed comprehensive optimization approach is shown to be an effective method of comparing a wide range of design alternatives for pipeline projects and identifying the one that optimizes the overall cost.
\end{abstract}

Keywords: Pipeline project optimization; Pipeline life cycle cost; Pipeline design; Pipeline project management.

\section{INTRODUCTION}

Water pipeline systems are designed to economically deliver water from source to consumer in sufficient quantity, of acceptable quality, at appropriate pressure. In order to achieve effective operation, critical loading conditions are first chosen and then optimization methods are often applied to select the most economical set of system properties that will produce the desired range of pressures in the network. Pipeline design is typically based on steady-state flow conditions (Moneim et al., 2010; Mansouri et al., 2015; Saminu et al., 2015), with the assumption that the cost of controlling transient pressures represents a small portion of the overall pipeline cost. However, transient investigation of various surge protection strategies can consider a variety of design options, which may include alternative pipeline routes, various pipe material and diameter choices and many other factors (Jung and Karney, 2020).

Transient analysis has been often left until the design and even construction process is well advanced. However, transient considerations are fundamental, not incidental, in determining the ultimate system performance and cost. A few studies have addressed the optimization of pipe networks for both steady-state and transient flow conditions. Laine and Karney (1997) applied optimization to a simple pipeline system consisting of a pipe connecting a pump to a storage tank. A complete enumeration procedure combined with a probabilistic selection procedure was incorporated into steady-state and transient analyses. Lingireddy et al. (2000) demonstrated that a specific surge tank design model can produce an optimal set of decision variables while meeting a predetermined pressure constraint. Matringe (2004) 
showed a surge protection design with a combination of a smaller pressure vessel and air valves. Boulos et al. (2005) presented a detailed flowchart for unsteady flow analysis. The chart aids in the selection of components for pressure surge control and suppression in pipelines and water distribution systems (WDSs). They suggested that transient analysis should be performed to assess the impact of each proposed strategy on network performance and operation. Djebedjian et al. (2005) and Afshar (2006) presented the optimization of pipe networks for both steady-state and transient flow conditions based on pipe size only. Jung and Karney (2006) used Genetic algorithms (GAs) and particle swarm optimization (PSO) for optimizing the use of surge protection devices with respect to their number, sizes, and locations. Jung et al. (2007) showed that it is important to carry out systematic transient analysis to resolve complex transient characterizations and to adequately protect a WDS. Espert et al. (2008) presented an air inlet valve combined with a double-acting air valve of low air discharge capacity, which can replace a surge tank. Jung et al. (2011) demonstrated the modifications of pipe size in the design process can result in an effective and inexpensive surge control strategy. Al-Khomairi et al. (2020) discussed pipeline project lifecycle cost optimization by considering pipe diameter, pipe material, surge tank size, and operation and maintenance cost throughout project service life. The authors used a unified project service life for different pipe materials.

This study, compared to Al-Khomairi et al. (2020), used a different lifespan with equivalent real annual cost (ERAC) for each design alternative rather than the present value used by Al-Khomairi et al. (2020). Furthermore, this study used another real-world project with a larger pipe diameter than that of Al-Khomairi et al. (2020). The impact of different pipe diameters is studied with each cost component on overall project cost. In this study, it is highlighted to evaluate capital, operational, and maintenance costs, each in equivalent real annual cost (ERAC) for the combination of pipe and surge protection device parameters in a search space of optimization. The ERAC is an improved cost form to compare alternatives with different lifespans considering the presence of inflation. In addition, an economic assessment of system performance is conducted with the costs of high and low pressures.

\section{METHODOLOGY}

A GA-based optimization technique was developed for the optimal design of long water supply pipelines, including optimal surge protection based on surge tanks. The objective function of GA optimization is to minimize the ERAC of the pipeline, pumps, surge tank and pipe maintenance, and pump operational energy over the predetermined service life of each project component. The primary constraints for the optimization problem involve pipe velocities and nodal pressures. Constraint violations are handled through penalty functions so that the optimization technique will always produce an optimal solution. Although pressure and velocity constraints are slightly violated, appropriate information is provided on the magnitude of each violation in terms of the penalty cost.

In general, surge tank is the most expensive among surge protection methods. The proposed optimization technique was aimed at optimizing the sizing of a surge tank for a given pipeline system. The primary variables that control the size of a surge tank are the initial gas volume and connection resistances for inflow and outflow. While the size of a surge tank depends on several factors associated with transmission main, the steady-state velocity in the pipeline can have the most significant influence on the size of the surge tank. The steady-state velocity depends on the size (diameter) of the pipeline. When the size of the pipeline is once decided, pressure rating may be selected to satisfy the appropriate pressure constraints. In addition, pipes of different materials may have different costs and, more importantly, different associated celerity (wave speed) values. Therefore, it is prudent to include pipe diameter, material, and pressure rating in the decision variable set.

The optimization procedure, which is implemented in a specially designed program, includes five decision variables: two decision variables associated with the surge tank (the initial gas volume and connection resistance) and three decision variables associated with the pipeline (diameter, material, and pressure rating). The first two decision variables are any real number (decimal values), while the remaining three are specific values selected from a list of suitable and available pipe data. After legitimate optimal solutions are obtained from the GA, further analysis is 
performed to consider the pump's initial costs, the pump's future operational costs, and future pipe maintenance costs for the pipe over a predetermined service life, which is expressed as the ERAC.

In the GA optimization, pipe data (i.e., diameter, material, and pressure rating) are selected from specified (e.g., commercially available) pipe characteristics table. Steady-state and transient constraints are calculated by external steady-state and transient analysis programs, respectively. Once a vector of optimal solutions is obtained using the GA (i.e., optimal with respect to pipe material, diameter and surge tank), further optimization is performed by adding the operational and maintenance costs of project over predetermined service life for each pipe material. Total cost for each solution is obtained in terms of the ERAC and then all GA solutions are arranged from best fit to least fit based on their ERAC values.

\section{CASE STUDY \\ Project Description}

In this study, a real-world project is selected to obtain a comprehensive optimum design. In this real-world project, raw water is obtained from a deep-well aquifer and pumped to a location close to Najran City in southern Saudi Arabia. The length of the pipeline is $109.2 \mathrm{~km}$. This is one of several similar projects being carried out by the Saudi Ministry of Environment Water and Agriculture (MEWA). Because of the rapid change in topography, three intermediate pumping stations are used. Well fields deliver raw water to tank A, and then, pumps are used to pump water from tank A to tank B, from tank B to tank C, and from tank C to tank D, all of which are located close to Najran City. Figure 1 shows a schematic diagram of the system. The normal required flow rate is $2,083 \mathrm{~m}^{3} / \mathrm{h}$. Table 1 summarizes a few key parameters for this real-world project.

The following water parameter values were used:

Temperature $=50^{\circ} \mathrm{C}$

Density $=990.2 \mathrm{~kg} / \mathrm{m}^{3}$

Kinematic viscosity $=0.605 \mathrm{E}-06 \mathrm{~m}^{2} / \mathrm{s}$

Bulk modulus $=0.2290 \mathrm{E}+10 \mathrm{~N} / \mathrm{m}^{2}$

Table 1. Parameters of the Pipelines Installed in the Case Study Project.

\begin{tabular}{ccccccccc}
\hline Pipeline & $\begin{array}{c}\text { Pipe } \\
\text { material }\end{array}$ & $\begin{array}{c}\text { Length } \\
\mathbf{( m )}\end{array}$ & $\begin{array}{c}\text { Diameter } \\
\mathbf{( m m})\end{array}$ & $\begin{array}{c}\text { Pipe thickness } \\
\mathbf{( m m})\end{array}$ & HWC $^{\text {a }}$ & $\begin{array}{c}\text { Wave } \\
\text { Speed (m/s) }\end{array}$ & $\begin{array}{c}\text { Pump rated } \\
\text { head (m) }\end{array}$ & $\begin{array}{c}\text { No. of } \\
\text { pumps }\end{array}$ \\
\hline A-B & Ductile Iron & 43,572 & 800 & 11.7 & 130 & 1072 & 200 & 4 \\
B-C & Ductile Iron & 38,502 & 800 & 11.7 & 130 & 1072 & 200 & 4 \\
C-D & Ductile Iron & 27,133 & 800 & 11.7 & 130 & 1072 & 135 & 3 \\
\hline
\end{tabular}

\footnotetext{
${ }^{a}$ Hazen-Williams coefficient.
} 


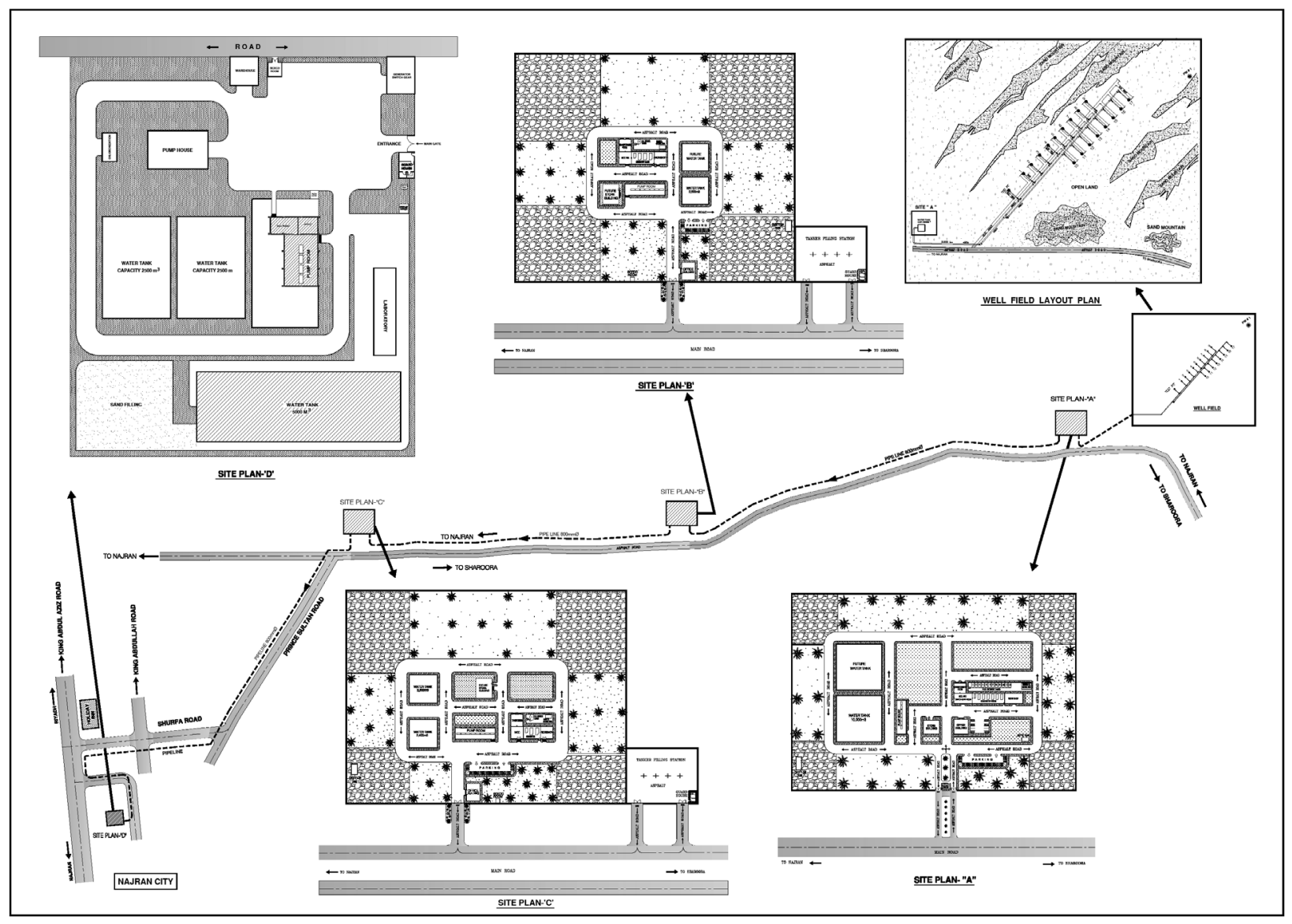

Figure 1. Schematic of the system considered in the case study.

\section{Hydraulic Analysis}

\section{Pipeline Profiles}

Figure 2 shows the pipeline profiles, steady-state hydraulic grade lines (HGLs), and maximum and minimum HGLs recorded from a complete transient flow simulation for the three pipeline systems. The top chart is for pipeline $\mathrm{A}-\mathrm{B}$, the middle chart is for pipeline $\mathrm{B}-\mathrm{C}$, and the bottom chart is for pipeline $\mathrm{C}-\mathrm{D}$. The maximum elevation difference between the highest and lowest points is approximately $105 \mathrm{~m}$ for pipeline A-B, $115 \mathrm{~m}$ for pipeline B-C, and $68 \mathrm{~m}$ for pipeline C-D. From a hydraulic point of view, these values are considered to be extremely large changes in profiles. Thus, the construction of intermediate groundwater tanks was suggested by the hydraulic studies conducted by the MEWA. 

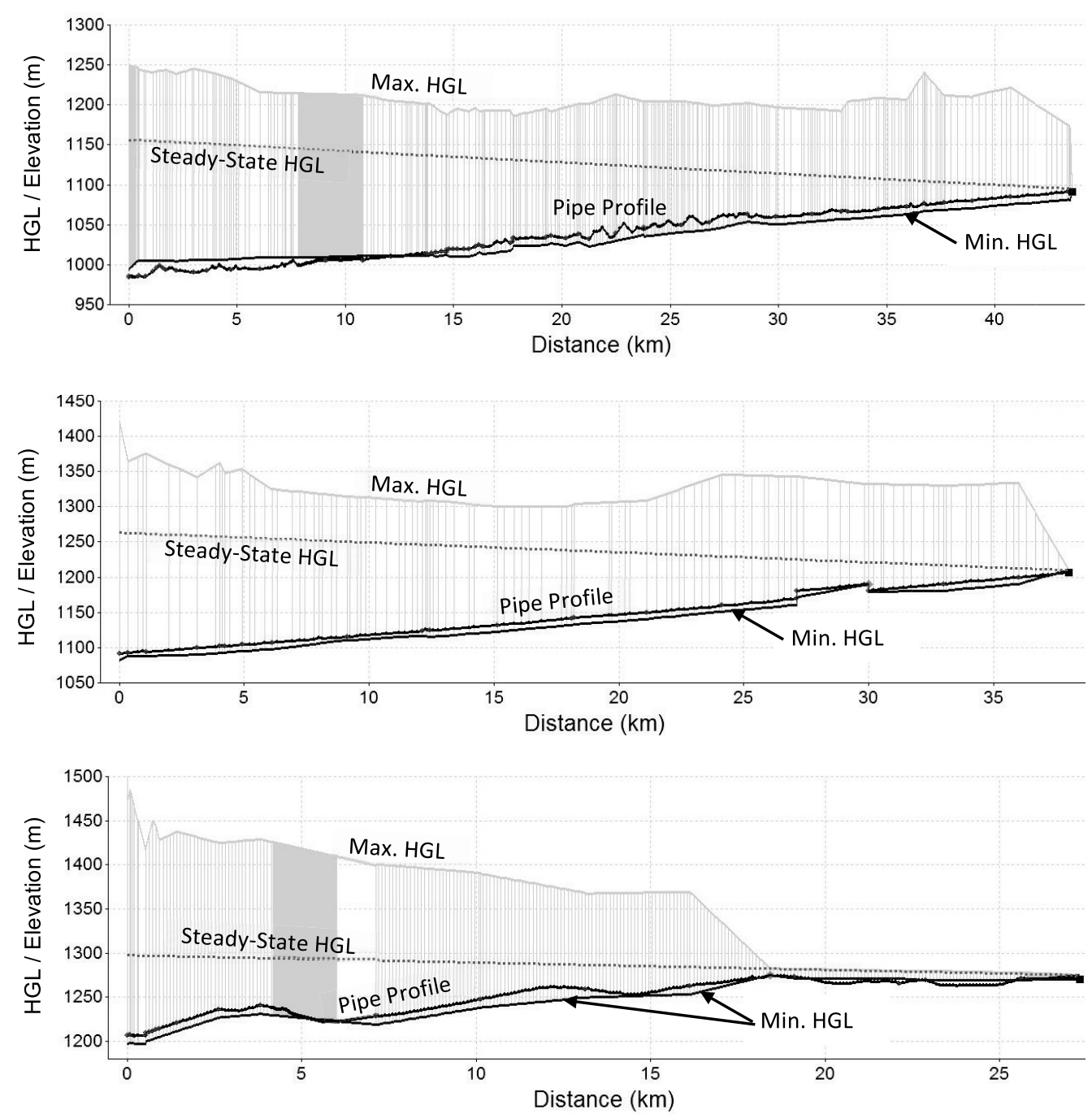

Figure 2. Steady-state, maximum, and minimum hydraulic grade lines (HGLs) without protection: (top) pipeline A-B, (middle) pipeline B-C, (bottom) pipeline C-D.

\section{Transient Event}

Pump trip is a transient event that cannot be avoided in the real world and may result from pump failure or power outage. For this reason, the hydraulic analysis in this study includes simulating a pump trip by fully closing a valve just downstream of the pump in $2 \mathrm{~s}$. This event is considered for each solution suggested by the GA in search for the best fit design. This event causes extreme low and high pressures, which may exceed constraints for some design alternatives; hence, there is a need to apply a penalty to their costs of the design alternatives.

\section{Hydraulic Grade Lines}

Figure 2 shows the maximum and minimum HGLs without protection. These HGLs were obtained using steadystate and transient flow simulations. Each point along the maximum and minimum HGLs show the maximum and minimum pressure heads recorded at that point throughout the simulation period, respectively. 


\section{Cost Evaluation}

In this study, the initial pipe cost included material, transportation, and installation costs. All project costs (initial, maintenance, and operational) were first calculated using net present values (NPVs). Comparing the NPVs of the alternatives would be inappropriate with unequal service lives and in the presence of inflation. As stated previously, an improved approach to handle alternatives with different lifespans in the presence of inflation is to convert the cost from NPVs to ERAC.

\section{Interest and Inflation Rates}

In the following cost analysis, the average historical values of the interest and inflation rates are considered as $3.7 \%$ and $2.8 \%$, respectively.

\section{Service Lives of Pipes and Pumps}

To evaluate the total cost, it is necessary to consider a reasonable service life for each project component. The average service life for ductile iron pipes (DICL) pipes under harsh ground conditions and early laying practices is 55.8 years, and the corresponding value for benign ground conditions and evolved laying practices is 109.6 years. For mild steel cement-lined (MSCL) pipes, the expected service life is 86.3 years (AWWA, 2012). The relevant value for glass fiber reinforced plastic (GRP) pipes is 60 years. Since the pipeline considered in the case study is installed under dry and benign soil conditions, 110, 86, and 60 years were considered as the expected service lives of the DICL, MSCL, and GRP pipe materials, respectively. The service life for pumps was assumed to be 25 years. This means that after every 25 years, the cost of a new set of pumps is added to the overall cost in the cost analysis. All of the costs are considered as NPVs considering the inflation and discount rate. Then, they are converted to ERAC to allow a proper comparison among the solution alternatives.

\section{Initial, Operational, and Maintenance Costs}

The objective of cost estimation is to facilitate investment decisions. To compare projects with different service lives, one could use replacement chain approach, which entails calculating the total net present value (NPV) over the lifecycle for each alternative. However, the total cycle for this case study would be as long as 60, 86, and 110 years; therefore, the different lifecycles taking inflation and interest rates into account make difficult to compare the cost of alternatives. A simpler approach, which yields identical results to the replacement chain method, is called equivalent annual cost (EAC). It is the annual cost of owning, operating, and maintaining an asset over its entire life. It allows a comparison of the cost effectiveness of various assets with unequal lifespans. The EAC is the annual cost of the project if it were to be paid as an installment at the end of each year over the whole project service life.

In the presence of inflation, the analyst considered rising prices due to inflation when calculating the NPV over the lifecycle using the replacement chain approach. For instance, consider that the GRP pipe project needs to be replaced after 60 years. One can use the NPV for the first period of the project and apply inflation to it to obtain the NPV for the second period (i.e., $\left.N P V_{2}=N P V_{1}(1+\text { inflation })^{60}\right)$ and so on for the following periods. The EAC approach can be modified to provide results identical to those of the replacement chain method (in the presence of inflation), namely, ERAC. Using ERAC instead of EAC enables to account for inflation. Thus, any NPV can be converted into the ERAC using the following equation:

$$
E R A C=\frac{N P V}{A_{f}}
$$

where $N P V$ is the net present value of the total cost or any present value of any cost (maintenance, operational, or capital), and $A_{f}$ is the present value annuity factor for real rate $r$ and economic life $n$, which is given by

$$
A_{f}=\frac{1}{r}\left(1-\frac{1}{(1+r)^{n}}\right)
$$

Here, $n$ is the project life length (e.g., years) and $r$ is the real rate, which is given by 
$r=\frac{d+1}{f+1}-1$

where $f$ denotes the average inflation rate expected during the lifetime of the pipeline project, and $d$ refers to the average interest (discount) rate expected during the lifetime of the project. The project with the lower ERAC is a better investment. Total costs can thus be compared in the same manner. The ERAC approach is much simpler than the replacement chain approach, and thus, is used in this case study.

The cost components for the project and the manner of their computation are described below.

i) Initial Cost of the Pipe, Surge Tank, and Pump

This cost component includes the initial price of the pipe, as well as its transportation, excavation, and installation costs. This cost is already expressed in terms of NPV. A survey was conducted to obtain the initial cost of the pump. According to this survey, the average initial pump price is $\$ 250 / \mathrm{kWh}$ input energy. The input energy is computed by dividing the output energy by the assumed pump efficiency ( $80 \%$ ). The initial cost of the first pump is already expressed in terms of NPV so converted to ERAC. When the service life of the pump set is over, a replacement set is to be installed so its cost is to be expressed in ERAC. The cost of the surge tank is estimated using the average cost per cubic meter obtained from actual surveys. Thus, the initial cost of the pipe, surge tank, and pump in ERAC is given by

$$
C_{I C}=\frac{1}{A_{f}}\left(C_{P I}+C_{S T}+\sum_{k=0}^{N P S-1} \frac{\left(C_{P U 1}\right)(1+f)^{l \times k}}{(1+d)^{l \times k}}\right)
$$

where $C_{I C}$ refers to the total initial cost of the pipe, protection surge tank, and pump in ERAC, $C_{\mathrm{PI}}$ is the initial cost of the pipe, $C_{S T}$ refers to the initial cost of the surge tank, and $k$ denotes the number of pump sets to be installed during the project service life (including the first pump set). NPS refers to the number of pump sets expected to be installed during the lifetime of the pipe, $C_{P U I}$ denotes the cost of the first pump set (already expressed in terms of NPV), and $l$ denotes the assumed lifetime of the pump set in years. Multiplying the current pump set price $C_{P U l}$ by $(1+f)^{l \times k}$ applies the effect of inflation. Thus, one would obtain the cost in a future year. Dividing the resulting number by $(1+d)^{l \times k}$ converts the number to the NPV. Dividing the result by $A_{f}$ gives the corresponding ERAC for the cost.

\section{ii) Pump Energy Cost}

Pump energy cost is estimated using the current energy cost per kWh. It is necessary to apply inflation to the current energy cost to estimate the energy cost for each year of the project service life. The resulting total energy cost is expressed in terms of NPV using the interest rate and then converted to the ERAC. The following equation shows how inflation and interest rates are utilized to estimate the ERAC of pump energy.

$$
C_{W p}=\frac{1}{A_{f}}\left(\sum_{i=1}^{n} \frac{\left(C_{W p 0}\right)(1+f)^{i}}{(1+d)^{i}}\right)
$$

where $C_{W p}$ denotes the pump energy cost as the ERAC, $C_{W \mathrm{p} 0}$ denotes the pump energy cost just before the start of the project (in this case, $C_{W P 0}=\mathrm{US} \$ 0.0408 / \mathrm{kWh}$, already in terms of NPV), $i$ denotes the year for which the energy cost is computed, $n$ refers to the length of the project life, and $f$ and $d$ are as defined earlier. Again, applying inflation is mandatory because the prices rise each year. Dividing the result by $(1+d)^{i}$ converts the cost to the NPV, and dividing it by $A_{f}$, converts the NPV of the total energy cost throughout the service life of the project into the ERAC.

\section{iii) Pipe Maintenance Cost}

The pipe maintenance cost includes all the expected repair costs, including replacing short segments of pipes (6 m or $12 \mathrm{~m}$ in length). It is calculated using the following equation:

$$
C_{M}=\frac{1}{A_{f}}\left(\sum_{i=1}^{n} \frac{\left(h_{i}\right)(L)\left(F_{C 0}\right)(1+f)^{i}}{(1+d)^{i}}\right)
$$


where $C_{M}$ refers to the pipe maintenance cost during its service life in terms of the $E R A C, h_{i}$ refers to the hazard rate (failures per meter per year) for year $i$ and is usually obtained from prediction hazard models, $L$ denotes the length of the pipe under consideration, $F_{C 0}$ refers to the current cost (just before operation starts) to repair a pipe failure, and $f, d$, and $n$ are as defined earlier.

\section{Hazard Rate}

The hazard rate ( $h$ in Eq.6) is known to follow a bathtub shape pattern for engineering structures over their service life. It mainly consists of three phases. Phase I is the burn-in period. It is a very short phase where the hazard (failure) rate starts somewhat high before it normalizes. This phase can be neglected as it is usually observed for a very short duration. Phase II has a constant failure rate due to pure random factors pertaining to pipe manufacturing, and random soil and stress conditions. Phase III is called the wear-out period and is characterized by escalating failure rates due to joint contribution of the pipe's ageing and other random factors. One way to handle such mixed distributions (while ignoring Phase I) is presented by the piece-wise hazard model for linear assets, as proposed by Sun et al. (2011):

$$
h(t)=\left\{\begin{array}{cl}
\lambda \quad, & 0 \leq t<\xi \\
\lambda+\frac{\beta(t-\xi)^{\beta-1}}{\alpha^{\beta}} x, & t \geq \xi, \alpha>0, \beta>1
\end{array}\right.
$$

where $h(t)$ is the hazard (failure) rate, $\lambda$ is a constant failure rate, $t$ is time, $\xi$ is the start time of Phase III, and $\beta$ and $\alpha$ are the shape and scale parameters of the Weibull distribution in Phase III, respectively.

\section{Modeling Failure Rate}

In this study, three materials are used as candidates for pipe materials: DICL, MSCL, and GRP. Li (2013) discussed a case study from a water utility in Queensland to test hazard prediction models. He collected and analyzed 10-year failure data containing 6,687 instances of valid repair history. The empirical hazard histories for DICL, MSCL, and GRP pipes given in the bar chart in Figure 3 are used in this study to obtain the fitted piecewise hazard model curve (using Eq. (7)). The imperial hazard histories for GRP and DICL pipes are somewhat similar, and thus, the two materials can be treated as one group to obtain the constants $\lambda, \beta$, and $\alpha$ in Eq. (7). However, MSCL pipes are different compared to the others so treated separately. Table 2 shows the values that provide the best fitted piecewise hazard model for the two groups. Using these constants, the prediction model equation can establish the hazard rate versus pipe age (years), as shown in Figure 3. This figure is used to estimate the hazard for each year for each pipe. The result is used to estimate the maintenance cost (Eq. (6)). The failure rate is multiplied by the pipe length to obtain the average number of failures:

$$
N_{F}=h(t) \times L
$$

where $N_{F}$ refers to the number of failures in a given year, $h(t)$ is the hazard rate for the considered year, and $L$ is the pipe length. The number of failures is multiplied by the cost to repair a failure, resulting in the maintenance cost.

Table 2. Parameters for the Best Fitted Piecewise Hazard Model for the Three Pipe Materials.

\begin{tabular}{lcccc}
\hline Material & $\boldsymbol{\lambda}$ & $\boldsymbol{\alpha}$ & $\boldsymbol{\beta}$ & $\boldsymbol{\xi}$ \\
\hline DICL and GRP & 0.0000334 & 5100 & 1.25 & 28 \\
MSCL & 0.0000312 & 4900 & 1.25 & 25 \\
\hline
\end{tabular}




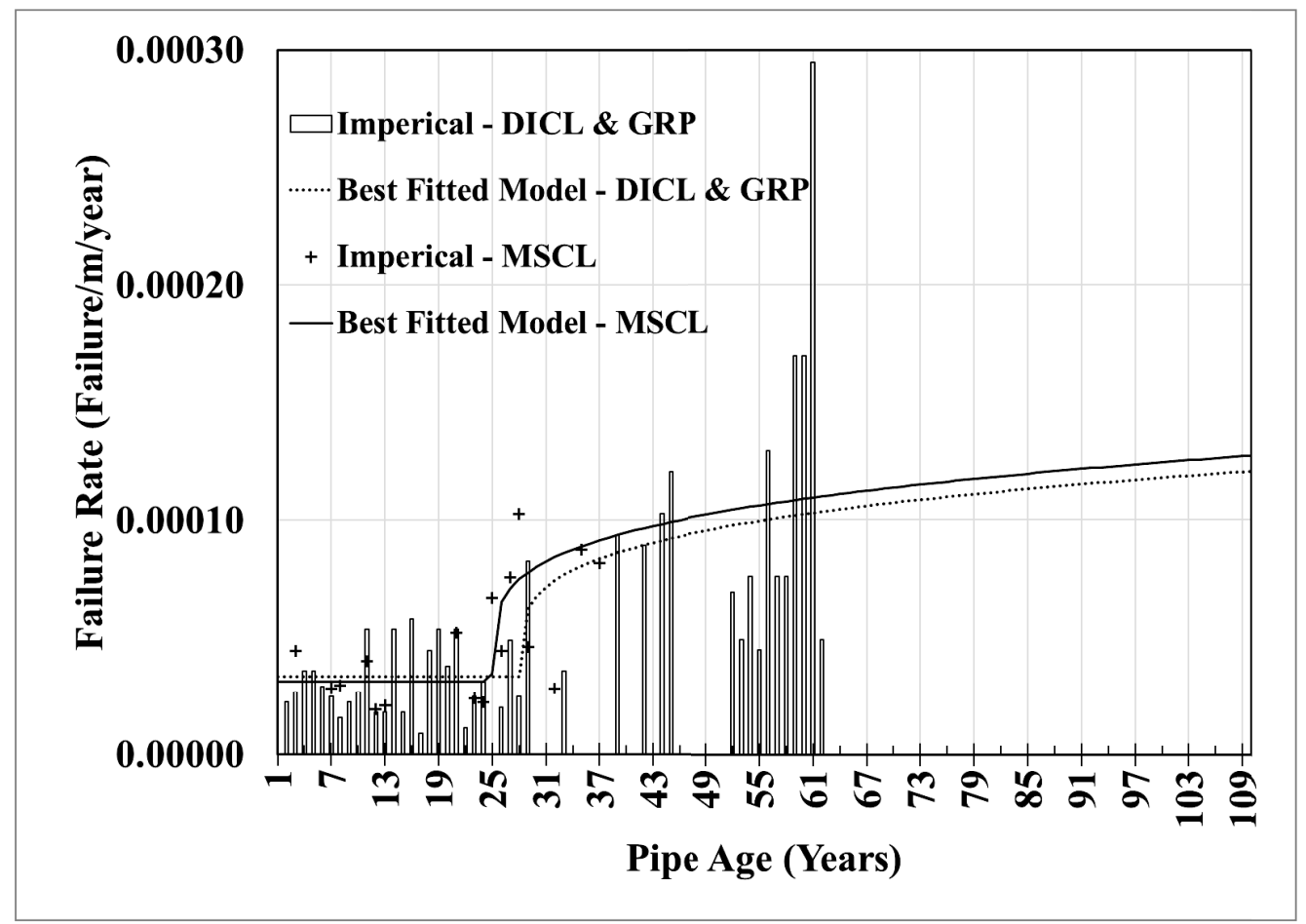

Figure 3. Empirical hazard histories for DICL, MSCL, and GRP pipes of Queensland and modeled hazard rate.

\section{Total Project ERAC}

Thus, the total project cost, expressed as the ERAC, is given by

$$
C_{T}=C_{I C}+C_{W p}+C_{M}
$$

The project with lower $C_{T}$ was chosen over those with higher $C_{T}$. A larger pipe size translates into lower operational energy costs and vice versa. Other factors, namely pipe material and surge tank size, can directly affect $C_{T}$. Thus, one needs to search for the optimum solution (i.e., find alternatives with the least $C_{T}$ ), while hydraulic constraints are not violated.

\section{RESULTS AND DISCUSSION}

All cost components mentioned earlier were summed to obtain the ERAC for each trial solution. Table 3 lists the actual ERAC for each of these components. The costs for each item were estimated using the methods discussed earlier in Eqs. (4) to (9). The objective was to search for the least expensive design using the optimization procedure described previously and to compare their costs to the actual costs.

Optimization identified many design alternatives and the costs of some designs were less than the actual as-built costs, as summarized in Table 3. Some of these alternatives were rejected because they violated one or more of pressure and velocity constraints. The five cost components of each acceptable design (see Eq. (9)) were initially obtained in terms of the NPV, converted to the ERAC, and added to obtain the total ERAC ( $C_{T}$ in Eq. (9)). Figure 4 shows a list of solution alternatives for pipeline B-C arranged in ascending order based on the $C_{T}$ values. For readability, only the best 160 trial solutions were considered. Figure 4 (top panel) shows the most important hydraulic parameters and constraints for each of the solutions, such as the minimum and maximum pressure resulting from both the steady-state and transient analyses (discussed earlier). It also shows the initial gas volume of surge tank and its lower and upper 
bounds. Furthermore, the figure depicts required pump pressure as well as pump power for each solution. Figure 4 (bottom panel) shows the cost aspect for the same trial solutions in the order depicted in the upper panel of the figure. The horizontal axis represents the trial solution number. The secondary vertical axis shows the penalty applied because of constraint violation. The primary vertical axis denotes the five cost components mentioned earlier (see $C_{T}$ in Eq. (13)). The first reading in Figure 4 (bottom panel) shows the optimal ERAC (US\$0.63 million). Total cost includes the ERAC of the five cost components as well as the penalty cost. Note that when the pipe cost decreases with a smaller diameter selection, the pump initial cost and energy cost increase, and vice versa. It is clear that when the pressure exceeds the lower or/and upper bound(s), the penalty cost increases. The bottom of the figure shows the material type as a letter (M for MSCL, G for GRP, and D for DICL) and the pipe diameters ( 8 for $800 \mathrm{~mm}, 9$ for $900 \mathrm{~mm}, 10$ for $1000 \mathrm{~mm}$, and 12 for $1200 \mathrm{~mm}$ ). The material and diameter symbols are depicted in two rows each for clarity. The first best 12 solutions are attributed to the MSCL pipe of diameter between 900 and $1200 \mathrm{~mm}$. The lowest cost design alternatives for each pipe material are listed in Table 4. It is evident that when selecting the DICL material, the revised design resulted in $8.5 \%$ savings compared to the as-built project cost, although the same pipe material was used. This result is attributed mostly to the over-designed pump power as well as cost optimization of the surge tank size and connection resistance. The overall saving achieved with the GRP pipe is $16.3 \%$. Using MSCL material resulted in a remarkably high saving of $31.1 \%$ in terms of the project ERAC compared to the data for the as-built DICL material. In other words, selecting DICL over MICL could result in an increase of 33.2\% in cost (with both designs optimized). This is mainly due to the lower cost of the MICL pipe material.

Table 3. Estimated As-built Equivalent Annual Costs (ERAC) (US\$, millions) for the Pipelines of the Case Study under Consideration.

\begin{tabular}{lccc}
\hline Component cost/pipeline & $\begin{array}{c}\mathbf{A}-\mathbf{B} \\
(\mathbf{L}=\mathbf{4 3 . 6} \mathbf{~ k m})\end{array}$ & $\begin{array}{c}\mathbf{B}-\mathbf{C} \\
(\mathbf{L}=\mathbf{3 8 . 5} \mathbf{~ k m})\end{array}$ & $\begin{array}{c}\mathbf{C}-\mathbf{D} \\
(\mathbf{L}=\mathbf{2 7 . 1} \mathbf{~ k m})\end{array}$ \\
\hline Pipe with installation/transportation & 28.930 & 25.570 & 18.020 \\
Surge tank & 0.240 & 0.190 & 0.110 \\
Pump initial cost & 1.120 & 1.120 & 0.570 \\
Pump energy cost & 36.090 & 36.090 & 18.260 \\
Pipe maintenance & 2.680 & 2.340 & 1.680 \\
Total cost (NPV) & 69.060 & 65.310 & 38.640 \\
Real rate-based annuity factor $\left(A_{f}\right)$ from Eq. 6 & 70.436 & 70.436 & 70.436 \\
Total cost (ERAC) & 0.980 & 0.930 & 0.550 \\
\hline
\end{tabular}

Table 4. Optimal Cost in ERAC (US\$, millions) Obtained for Each Pipe Material.

\begin{tabular}{|c|c|c|c|c|c|}
\hline Pipeline & A-B & B-C & C-D & $\begin{array}{c}\text { Total project } \\
\text { cost }\end{array}$ & $\begin{array}{c}\text { Overall } \\
\text { savings }(\%) \\
\end{array}$ \\
\hline $\begin{array}{l}\text { Estimated as-built ERAC } \\
\text { (US\$, millions) }\end{array}$ & 0.98 & 0.93 & 0.55 & 2.46 & \\
\hline DICL & $\begin{array}{c}0.90 \\
(\mathrm{D}=800 \mathrm{~mm})\end{array}$ & $\begin{array}{c}0.83 \\
(\mathrm{D}=800 \mathrm{~mm})\end{array}$ & $\begin{array}{c}0.52 \\
(\mathrm{D}=800 \mathrm{~mm})\end{array}$ & 2.25 & 8.5 \\
\hline GRP & $\begin{array}{c}0.82 \\
(\mathrm{D}=900 \mathrm{~mm})\end{array}$ & $\begin{array}{c}0.76 \\
(\mathrm{D}=900 \mathrm{~mm})\end{array}$ & $\begin{array}{c}0.48 \\
(\mathrm{D}=800 \mathrm{~mm})\end{array}$ & 2.06 & 16.3 \\
\hline MSCL & $\begin{array}{c}0.66 \\
(\mathrm{D}=1200 \mathrm{~mm})\end{array}$ & $\begin{array}{c}0.63 \\
(\mathrm{D}=1200 \mathrm{~mm})\end{array}$ & $\begin{array}{c}0.40 \\
(\mathrm{D}=900 \mathrm{~mm})\end{array}$ & 1.69 & 31.3 \\
\hline
\end{tabular}




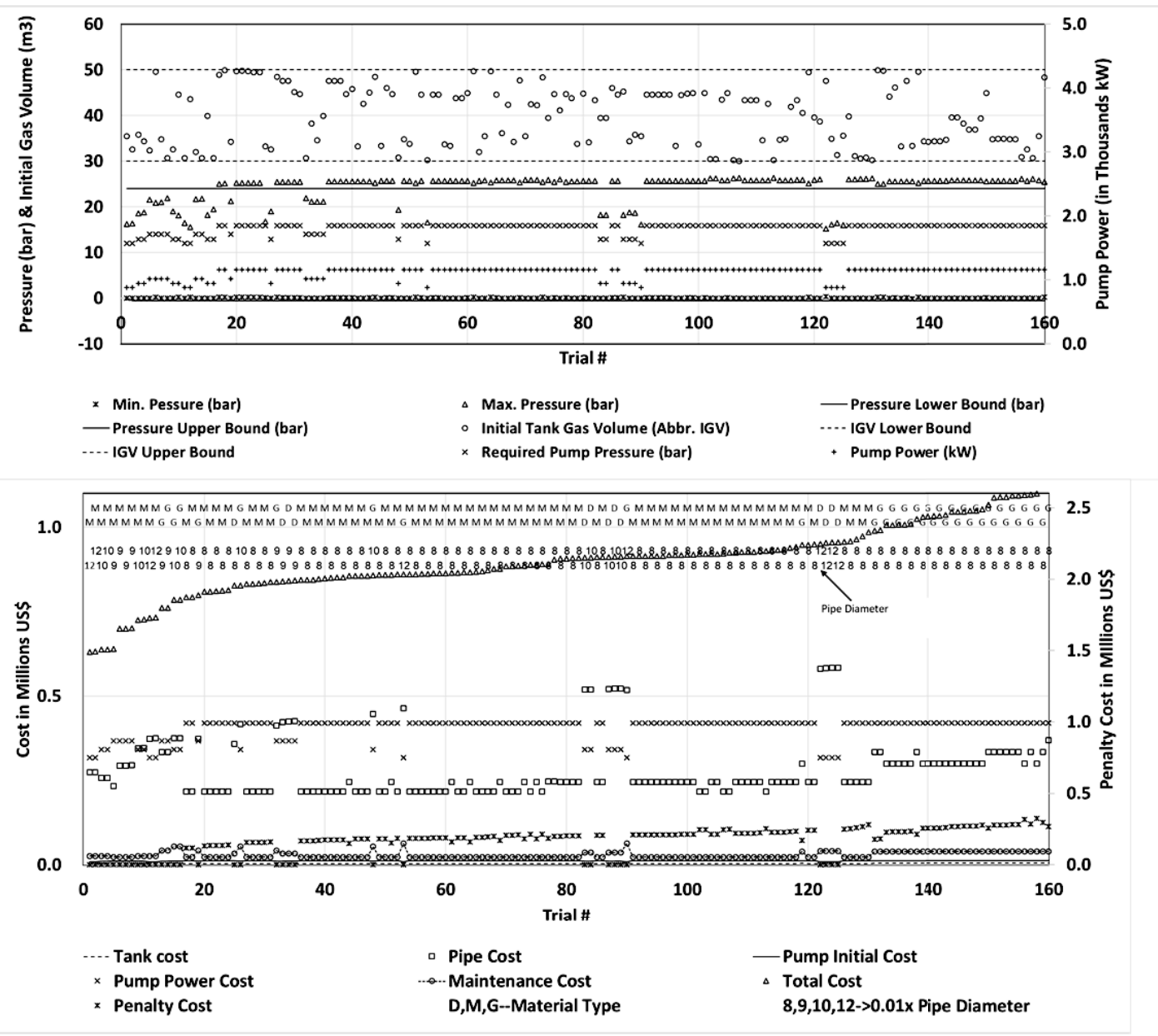

Figure 4. Sorted list of solution alternatives for sample optimization run for pipeline B-C.

Figure 5 shows the ERAC if only one of the three pipe materials (DICL, GRP, or MSCL) is considered for each of the three pipelines. The top panel shows the ERAC when only DICL material is available to install. The middle and bottom panels show the ERAC for GRP and MSCL, respectively. Unifying the material in this manner allows one to interpret the effect of the diameter on the cost. The first five bars in the top panel relate to pipeline A-B. The first bar is the cost estimate for the as-built pipeline (DICL of $800 \mathrm{~mm}$ diameter). The other four bars denote the four pipe sizes, as shown in the legend. The bars show the least-cost design (minimum $C_{T}$ ) for each pipe size that could theoretically be used without violating the project constraints. The top panel shows that the best pipe size when using DICL material is the $800 \mathrm{~mm}$ for all the three pipelines (A-B, B-C, and C-D). It is clear from Figure 5 (top panel) that to reduce the cost for DICL, which entails a high material cost, a pipe of a smaller diameter must be used (despite the higher energy cost). Figure 5 (bottom panel) shows that when MSCL material is used, the optimum diameter for A-B and B-C is $1200 \mathrm{~mm}$, while the optimum diameter for pipeline C-D is $900 \mathrm{~mm}$. A clear pattern emerges: the less expensive the material, the more economical it is to select higher diameter pipes and save on the energy cost. However, for shorter MSCL pipes (pipeline C-D), smaller diameters will be less costly (even at the expense of power). The optimal GRP cost lies approximately midway between that of DICL and MSCL in the sense that the best pipe size is $900 \mathrm{~mm}$ for $\mathrm{A}-\mathrm{B}$ and $\mathrm{B}-\mathrm{C}$ and $800 \mathrm{~mm}$ for C-D.

Figure 6 shows the effect of material on pipe cost when considering a constant pipe diameter. Figure 6(a) shows the cost when three materials are available for selection and only pipes of $800 \mathrm{~mm}$ diameter are allowed. It is clear that the 
least expensive material for all the three pipelines (A-B, B-C, and C-D) is MSCL, followed by GRP. Figure 6(b) shows the cost when considering a constant pipe diameter of $900 \mathrm{~mm}$, presenting MSCL is the least expensive material. The same conclusion applies for pipes of diameter $1000 \mathrm{~mm}$ and $1200 \mathrm{~mm}$ (Figures 8(c) and 8(d), respectively). When selecting DICL pipes of diameter $800 \mathrm{~mm}$ and larger (both using the optimized design), one would pay additional cost of $24 \%, 23 \%$, and $27 \%$ for pipelines A-B, B-C, and C-D, respectively, as seen in Figure 6(d). Choosing the least expensive diameter of MSCL over that of DICL could save $27 \%, 24 \%$, and $23 \%$ of the total cost for pipelines A-B, $\mathrm{B}-\mathrm{C}$, and C-D, respectively. Thus, for this case study, the longer the pipeline, the higher the saving if one were to use higher diameter MSCL over any other material. Similarly, selecting MSCL over GRP can result in savings of 20\%, $17 \%$, and $17 \%$ for these pipelines, respectively.

It is crucial to note that if the NPVs of the costs is used for comparison between project alternatives that have different lifespans, one may unintentionally select more expensive project alternatives. Thus, alternatives for projects with different lifespans should be carefully considered with using the ERAC.
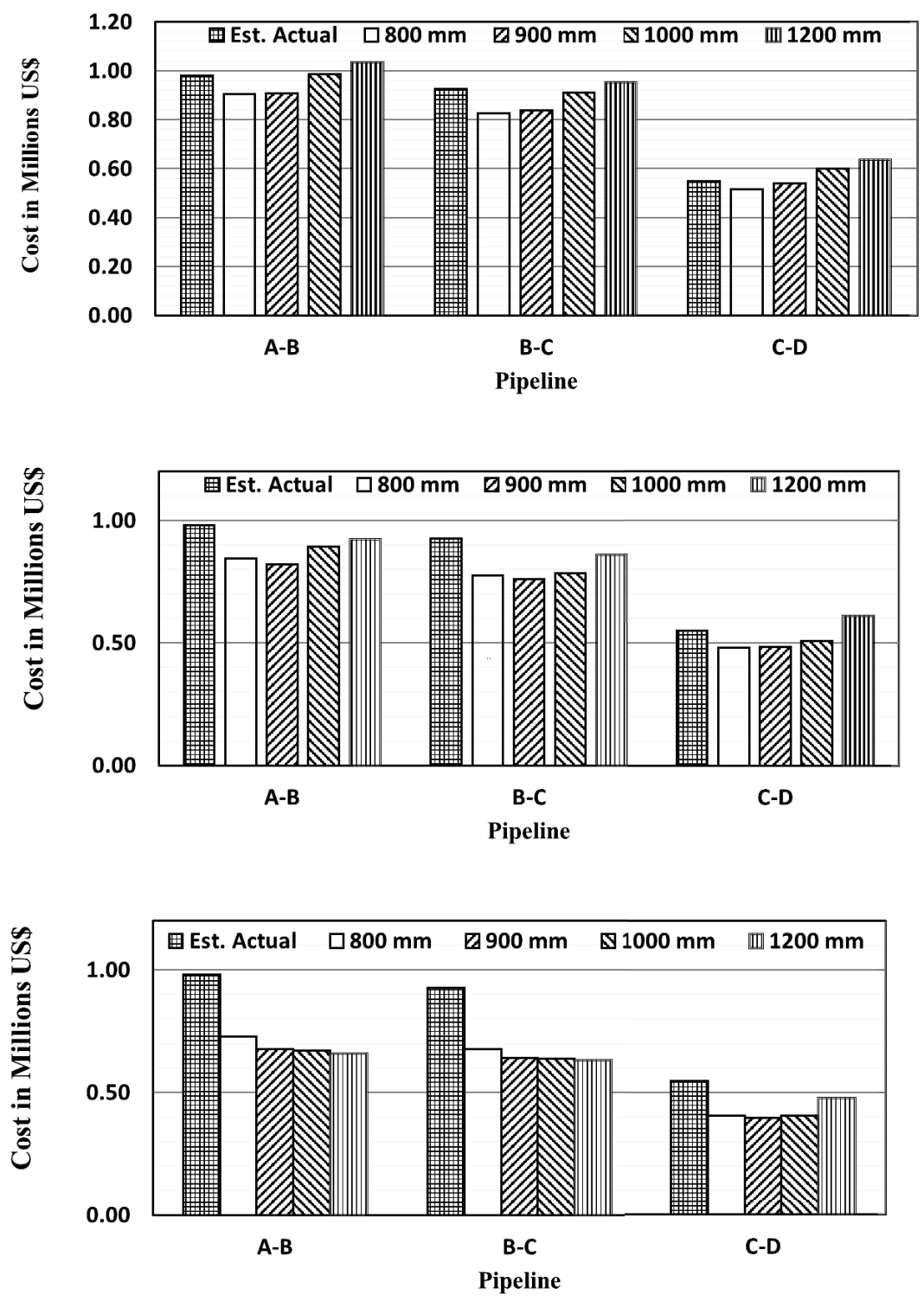

Figure 5. Project cost if one material is imposed on the design: DICL (top), GRP (middle), and MSCL (bottom). 

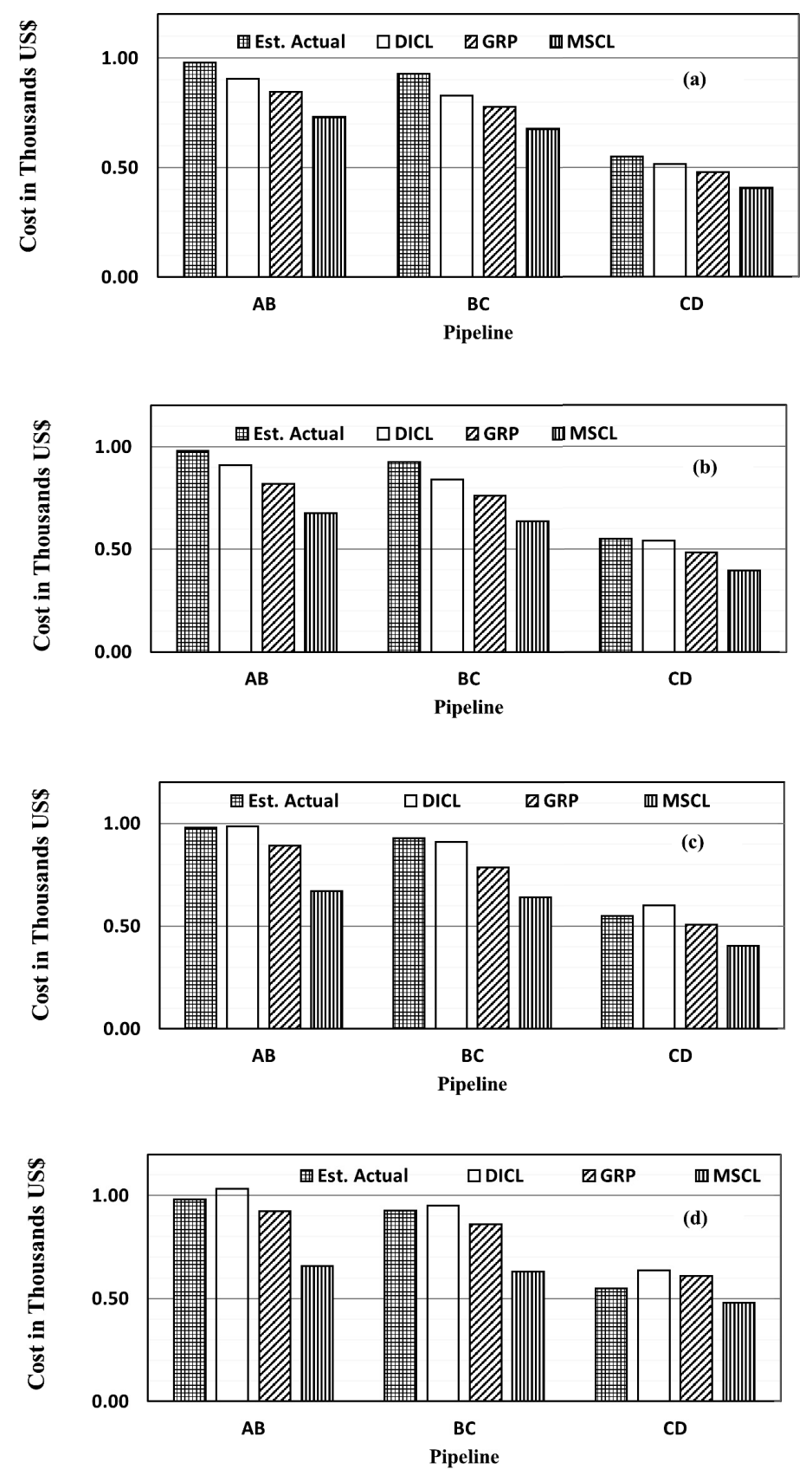

Figure 6. Project cost if a single diameter is imposed on the design for the whole project: (a) $800 \mathrm{~mm}$, (b) $900 \mathrm{~mm}$, (c) $1000 \mathrm{~mm}$, and (d) $1200 \mathrm{~mm}$.

\section{CONCLUSIONS}

Given the huge expenditure involved in building pipelines, cost optimization is an important issue in global construction industry. This study analyzed pipeline optimization in a more comprehensive manner than previous studies by extending solution search space to include pipe diameter, pipe material, surge tank size, pump initial cost, energy cost, and maintenance cost throughout project service life. Instead of using the NPVs of cost for comparing project alternatives, this study used equivalent real annual cost, which is a precise tool to analyze alternatives with different 
lifespans in the presence of inflation. A GA was implemented to search for the optimum cost of pipeline material, installation, and maintenance. In this approach, the GA-suggested design alternative is accepted as a candidate solution if it does not violate pressure and velocity constraints during steady-state and transient conditions associated with an extreme event. A real-world project was used as a case study. The results showed that the proposed comprehensive optimization approach could lead to remarkable savings, at least, for projects similar to the described case study of a long pipeline with a diameter of $800 \mathrm{~mm}$. The analysis of the case study showed that project cost can be considerably reduced by selecting a larger-diameter pipe to lower pump energy cost over project service life. This is more obvious when the pipe initial cost (material/installation) is lower. In addition, with the approach of equivalent real annual cost, this study can offer a clear, objective and unbiased comparison of costs toward any design alternatives. This paper, therefore, yields a more comprehensive assessment of the extent of variation in pipeline project costs with a wide search space for various parameters affecting overall cost.

\section{DATA AVAILABILITY STATEMENT}

Some or all data, models, or code generated or used during the study are available from the corresponding author by request. Some or all data, models, or code generated or used during the study are proprietary or confidential in nature and may only be provided with restrictions (e.g., anonymized data).

\section{ACKNOWLEDGMENT}

This project was supported by the National Science and Technology Plan (NSTP, Grant no. 10-BUI1275-02). The author would like to thank all the members at the NSTP office at King Saud University for their support and cooperation.

\section{Declaration of Conflicting Interests}

- None

\section{REFERENCES}

Afshar, M.H. 2006. Application of a max-min ant system to joint layout and size optimization of pipe networks. Engineering Optimization, 38(3): 299-317.

Al-Khomairi A., Jung B., and Elsebaie I. 2020. Lifecycle cost optimization of pipeline projects. Journal of Water Supply: Research and Technology - AQUA 69(7): 656-667.

AWWA. 2012. Buried no longer: Confronting America's water infrastructure challenge, Denver CO.

Boulos, P.F., Karney, B.W., Wood, D.J., and Lingireddy, S. 2005. Hydraulic transient guidelines for design, operation and protection of water distribution systems. Journal - American Water Works Association, 97(5): 111-124

Djebedjian, B., Mohammad, M., Mondy, A., and Abou Rayan, M. 2005. Network optimization for steady flow and water hammer using genetic algorithms. Proceedings of the Ninth International Water Technology Conference, IISD, Sharm ElSheikh, Egypt.

Espert, V., Garcia-Serra, J., and Koelle, E. 2008. The use of air valves as protection devices in pressure hydraulic transients. Proceedings of the Tenth International Conference on Pressure Surges, S. Hunt, ed., BHR Group, Edinburgh, UK.

Jung, B.S., Boulos, P.F., and Altman, T. 2011. Optimal transient network design: a multi-objective approach. Journal - American Water Works Association, 103(4): 118-127.

Jung, B.S., and Karney, B.W. 2006. Hydraulic optimization of transient protection devices using GA and PSO approaches. Journal of Water Resources Planning \& Management, ASCE 132(1): 44-52.

Jung, B.S., Karney, B.W., Boulos, P.F. and Wood, D.J. 2007. The need for comprehensive transient analysis of water distribution systems. Journal - American Water Works Association, 99(1): 112-123.

Jung, B.S., and Karney, B.W. 2020. Pressure surge control strategies revised. AWWA Water Science, 2(1): e1169. 
Laine, D.A., and Karney, B.W. 1997. Transient analysis and optimization in pipeline - a numerical exploration. Proceedings of the Third International Conference. on Water Pipeline Systems, R. Chilton, ed., Mechanical Engineering Publications, Hague, Netherlands.

Li, F. 2013. Multi-criteria optimization of group replacement schedules for distributed water pipeline assets. PhD thesis, Queensland University of Technology, Brisbane, Australia.

Lingireddy, S., Funk, J.E., and Wang, H. 2000. Genetic algorithms in optimizing transient suppression devices. Proceedings, ASCE 2000 Joint Conference on Water Resources Engineering and Water Resources Planning and Management, ASCE, Minneapolis, Minnesota.

Mansouri, R., Torabi, H., Hoseini, M., and Morshedzadeh, H. 2015. Optimization of the water distribution networks with differential evolution (DE) and mixed integer linear programming (MILP). Journal of Water Resource and Protection, 7(9): 715-729.

Matringe, J. 2004. Case study of a system with air valve problems. The practical application of surge analysis for design and operation. Proceedings of the Ninth International Conference on Pressure Surges, BHR Group, Chester, UK.

Moneim, M.A., Moawad, A.K., Molla, A.A., and Selawy, A.A. 2010. Relopt: Model application for reliability-based optimization for water distribution networks. World Engineering \& Applied Sciences Journal, 1(1): 1-8.

Saminu, A., Rabia, L., Tsoho, U., Haruna, I.G., and Faustinus, B. 2015. The least cost design of existing water distribution network for NDA using genetics algorithm. Global Journal of Advanced Engineering Technologies and Sciences, 2(2): 28-35.

Sun, Y., Colin, F., and Ma, L. 2011. Reliability prediction of long-lived linear assets with incomplete failure data. Xian China 2011 International Conference on Quality, Reliability, Risk, Maintenance and Safety Engineering, Xi'an, 2011. 